\title{
Ericoid mycorrhizal diversity increases with soil age and progressive phosphorus limitation across a 4.1 million-year chronosequence
}

\author{
Devin R. Leopold ${ }^{1,2^{*}}$, Kabir G. Peay ${ }^{1}$, Peter M. Vitousek ${ }^{1}$, Tadashi Fukami ${ }^{1}$
}

\begin{abstract}
Ericaceous plants rely on ericoid mycorrhizal fungi for nutrient acquisition. However, the factors that affect the composition and structure of these fungal communities remain largely unknown. Here, we use a 4.1-myr soil chronosequence in Hawaii to test the hypothesis that changes in nutrient availability with soil age determine the diversity and species composition of fungi associated with ericoid roots. We sampled roots of a native Hawaiian plant, Vaccinium calycinum, and used DNA metabarcoding to quantify changes in fungal diversity and species composition. We also used a fertilization experiment at the youngest and oldest sites to assess the importance of nutrient limitation. We found an increase in diversity and a clear pattern of species turnover across the chronosequence, driven largely by putative ericoid mycorrhizal fungi. Fertilization with nitrogen at the youngest site and phosphorus at the oldest site reduced total fungal diversity, suggesting a direct role of nutrient limitation. Our results also reveal the presence of novel fungal species associated with Hawaiian Ericaceae and suggest a greater importance of phosphorus availability for communities of ericoid mycorrhizal fungi than is generally assumed.
\end{abstract}

\footnotetext{
${ }^{1}$ Stanford University, Department of Biology, 371 Serra Mall, Stanford, CA 94305-5020, USA ${ }^{2}$ Oregon State University, Department of Botany and Plant Pathology, 4575 SW Research Way, Corvallis, OR, 97331, USA
}

*Correspondence: devin.leopold@gmail.com 


\section{Introduction}

Most plants in the family Ericaceae host a diverse assemblage of root-associated fungi and form a unique mycorrhizal symbiosis known as an ericoid mycorrhiza (ErM; D.R. Leopold, 2016; Perotto et al., 2012). The ErM symbiosis allows ericaceous plants to proliferate in harsh environments where acidic soils, low temperatures, or excessive soil moisture slow the degradation of organic matter and limit mineral nutrient availability (Read 1991; Cairney and Meharg 2003; Mitchell and Gibson 2006). In these harsh habitats, which can be found on every continent except Antarctica (Kohout 2017), ericoid mycorrhizal fungi (ErMF) facilitate nutrient cycling by degrading complex organic matter and providing their hosts with access to nutrient pools that would be unavailable otherwise (Nasholm et al. 1998; Wurzburger, Higgins and Hendrick 2012; Adamczyk et al. 2016; Perotto, Daghino and Martino 2018). Ericaceous plants and ErMF also contribute to carbon sequestration in these environments through the production recalcitrant plant litter and hyphal necromass (Clemmensen et al. 2013, 2015). However, despite the ecological importance of the ErM symbiosis, and significant functional variation within and among ErMF species (Cairney et al. 2000; Whittaker and Cairney 2001; Grelet et al. 2009b; Wurzburger, Higgins and Hendrick 2012), little is known about how factors such as soil nutrient availability affect the community composition of ErMF and other fungi associated with ericoid roots.

Currently, most data on ErMF originates from temperate and boreal regions, where cooler temperatures and repeated glaciation throughout the Pleistocene have maintained widespread nitrogen (N) limitation, even in late-successional ecosystems (Tamm 1991; Vitousek and Howarth 1991). As a result, research on ErMF has focused on their ability to utilize various 
organic N sources and influence host N status (Leake and Read 1991; Nasholm et al. 1998; Xiao and Berch 1999; Cairney et al. 2000; Grelet et al. 2009b; Ishida and Nordin 2010). However, the distribution of ericaceous plants is not limited by these habitat conditions (Leopold 2016; Kohout 2017) and there is evidence that ErMF also facilitate the uptake of phosphorus (P) and other mineral nutrients for host plants (Pearson and Read 1973; Read 1983; Myers and Leake 1996). This suggests that the relative availability of limiting nutrients in soil, $\mathrm{P}$ as well as $\mathrm{N}$, may influence ericaceous plant-fungal interactions and ErMF community composition (Hazard et al. 2014; Van Geel et al. 2020).

One source of natural variation in the availability of $\mathrm{N}$ and $\mathrm{P}$ in soil is pedogenesis, or long-term soil development. Over hundreds of thousands to millions of years, and in the absence of rejuvenating disturbance (Peltzer et al. 2010), pedogenesis causes predictable changes in ecosystem-level nutrient limitation, primarily through the accumulation of $\mathrm{N}$ from biological inputs and the progressive loss and occlusion of rock-derived nutrients, especially $\mathrm{P}$ (Walker and Syers 1976; Chadwick et al. 1999). These changes result in an initial, progressive phase, defined by $\mathrm{N}$ limitation of primary productivity and the rapid accumulation of organic matter; a mature phase, defined by maximal productivity and co-limitation by $\mathrm{N}$ and $\mathrm{P}$; and a retrogressive phase, defined by P limitation and reduced rates of nutrient cycling (Vitousek and Farrington 1997; Richardson et al. 2004; Wardle 2004; Peltzer et al. 2010).

Because the direct observation of long-term soil development in a single site is not possible, soil chronosequences, or gradients of soil age in which other putative controlling factors (i.e., parent material, climate, vegetation type, etc.) are held reasonably constant, can provide insight into the effects of changes in nutrient availability with soil age (Fukami and 
Wardle 2005; Lambers et al. 2008; Walker et al. 2010; Dickie et al. 2013). Soil chronosequence studies of arbuscular mycorrhizal fungi (AMF) have suggested direct $\mathrm{N}$ and $\mathrm{P}$ limitation of fungi in young and old ecosystems, respectively (Treseder and Allen 2002), and a peak in AMF richness at fertile, middle-aged sites (Krüger et al. 2015). However, AMF are primarily involved in mineral nutrient uptake (Smith and Read 2006) and appear to lack the extracellular enzymes needed to access the organic nutrient pools available to some ErMF (Tisserant et al. 2013). ErMF diversity could respond differently to changing mineral nutrient availability with soil aging, but the relative importance of $\mathrm{N}$ and $\mathrm{P}$ limitation for ErMF is currently unknown. Furthermore, despite adaptation of the ErM symbiosis to soils with low mineral nutrient availability, studies of ErMF from retrogressive, P-limited habitats are lacking (Dickie et al. 2013).

To explore the effects of long-term soil development on ErMF, and the broader community of ericaceous root-associated fungi, we sampled roots of a single ericaceous plant species, Vaccinium calycinum, across a 4.1 myr soil chronosequence in the Hawaiian Islands, known as the Long Substrate Age Gradient (LSAG; Vitousek 2004). The LSAG is a useful system to study ErMF for three reasons. First, $V$. calycinum, a common host plant species, is present at all LSAG sites. The prevalence of a common host species across the chronosequence controls for changes in host identity, which can influence the composition of mycorrhizal symbiont communities (Martínez-García et al. 2015), though intraspecific variation in host traits affecting plant-fungal interactions are also possible (Johnson et al. 2010). Second, vegetation at LSAG sites is dominated by a single canopy tree species and a common suite of understory plants (Kitayama and Mueller-Dombois 1995), which all form mycorrhizal associations with 
AMF (Koske, Gemma and Flynn 1992). The only other ericaceous species present at any of the LSAG sites, Vaccinium dentatum and Leptecophylla tameiameiae, occur very sparsely at all sites, which further limits the potential impact of changes in host vegetation along the chronosequence. Third, changes in nutrient limitation across the LSAG have been experimentally demonstrated through $\mathrm{N}$ and $\mathrm{P}$ fertilizer addition experiments (Vitousek 2004). Because these fertilization experiments are long-term and ongoing at the oldest and youngest LSAG sites, this system presents a unique opportunity to experimentally test whether ecosystemlevel nutrient limitation (i.e., $\mathrm{N}$ and $\mathrm{P}$ availability in young and old sites, respectively) plays a role in structuring communities of ericaceous root-associated fungi.

We began with the hypothesis that the diversity of fungi associated with ericaceous roots increases throughout long-term soil development, with ErMF diversity increasing owing to the accumulation of complex organic nutrient pools. We predicted that diversity would increase most rapidly during the early stages of pedogenesis due to the formation and development of an organic soil horizon and that an increase would continue into the retrogressive stages as soil weathering and occlusion of mineral nutrients promotes niche partitioning in the rhizosphere (Turner 2008; DeForest and Scott 2010). We also used long-term fertilization experiments to test the hypothesis that nutrient limitation of primary productivity, $\mathrm{N}$ at the youngest site and $\mathrm{P}$ at the oldest site, shapes the species composition of ErMF and other ericaceous root-associated fungi.

\section{Materials and Methods}

Study system 

questions about the mechanisms that control nutrient cycling and limitation throughout long-term soil development by exploiting the increasing age of Hawaiian volcanoes with increasing distance from the active hot spot (Vitousek 2004). Samples for the study reported here were collected from five LSAG sites ranging in substrate age from $300 \mathrm{yr}$ to 4.1 myr (Fig. 1). One site (1.4 myr) was not sampled due to logistical constraints. In this system, substrate age is an estimate of how long ago the parent substrate was deposited by volcanic activity. The locations of the LSAG sites were chosen to minimize variation in state factors other than the age of the soil substrate. All sites share similar initial parent substrate, occur on the constructional slope of a shield volcano, are $c a .1200 \mathrm{~m}$ asl, receive $c a .2500 \mathrm{~mm}$ rain annually, and have a mean annual temperature of $c a .16^{\circ} \mathrm{C}$ (for detailed site descriptions, see Crews et al., 1995; Vitousek, 2004). Biotic variation is also highly constrained across the LSAG. Vegetation consists of native forest dominated by the canopy tree species Meterosideros polymorpha, with an understory that includes Cheirodendron trigynum, Cibotium spp. (tree ferns), Coprosma spp., Ilex anomala, Myrsine spp., and V. calycinum (Kitayama and Mueller-Dombois 1995). addition experiments were established in some LSAG sites to experimentally test hypotheses concerning the dynamics of nutrient limitation to ecosystem processes over geologic time scales. Fertilization plots sampled for the current study were established at the 300-yr site in 1985 (Vitousek et al. 1993) and at the 4.1-myr site in 1991 (Herbert and Fownes 1995), and so had 108 been ongoing for 30 and 23 years, respectively, at the time of this sampling. At each site, 16 109 plots $(15 \times 15 \mathrm{~m})$ were randomly assigned to either an unfertilized control or treatments that 
received fertilizer in the form of $\mathrm{N}$ (initially half ammonium nitrate and half urea, since 2002 just urea), P (triple superphosphate), or both N and P. Fertilizer was applied twice a year until 2002 and biannually thereafter at a consistent annual rate of $100 \mathrm{~kg} \mathrm{ha}^{-1} \mathrm{yr}^{-1}$.

\section{Sample collection}

Sampling occurred in August 2014, with the exception of the nutrient addition plots at the 300 yr site, which were sampled in August 2013 as part of a preliminary feasibility study. To account for possible inter-annual variation, an additional 12 plants from non-fertilized plots at the 300 yr site were collected in 2014. Initial analyses suggested that samples from unfertilized plots collected at the $300 \mathrm{yr}$ site in different years had similar fungal communities. Nonetheless, comparisons across the chronosequence reported here utilize only the 2014 samples and analyses of samples from fertilizer plots involved comparisons within each site, using the 2013 samples for the $300 \mathrm{yr}$ site and the 2014 samples for the 4.1 myr site.

At each LSAG site, 12 mature $V$. calycinum plants were randomly selected within a 200 $\times 200 \mathrm{~m}$ area. In the fertilizer addition plots at the $300 \mathrm{yr}$ and $4.1 \mathrm{myr}$ sites, two plants were sampled in each $15 \times 15 \mathrm{~m}$ plot, resulting in 32 samples per site $(8$ samples per fertilizer treatment in each site). For each plant, a portion of the root system and the adhering soil was removed with a hand trowel and bagged for transport. Samples were refrigerated $\left(4^{\circ} \mathrm{C}\right)$ until they could be processed, always within 48 hrs of collection. Fine terminal roots were manually separated from the soil and rinsed in tap water to remove all visible soil particles and 12 segments, $c a$. $2 \mathrm{~cm}$ each, were randomly selected and pooled for each plant. Pooled root samples were surface sterilized by sequential vortexing for 1 minute in sterile water, $70 \% \mathrm{EtOH}, 50 \%$ 
132 household bleach, and then rinsed 3 times in sterile water. Surface sterilized roots were then

133 stored at $-80^{\circ} \mathrm{C}$.

134

135

136

137

138

139

140

141

142

143

144

145

146

147

148

149

150

151

152

153

Fungal community metabarcoding

Frozen roots were homogenized by bead beating in CTAB lysis buffer and total DNA was extracted using the Nucleospin Plant II kit (Macherey-Nagel). In order to provide negative controls for Illumina sequencing, 4 sterile bead beating tubes were processed in parallel with the tubes containing root samples. Following DNA extraction, the first half of the internal transcribed spacer region (ITS1) of fungal nrDNA was amplified using Illumina fusion PCR primers. Primers included the ITS1 primers ITS1F (forward) or ITS2 (reverse), modified to include Illumina adapters and a sample specific 12 bp, error-correcting Golay barcode (Smith and Peay 2014). PCR was carried out in $25 \mu$ reactions using $1 \mu 1$ of template DNA (diluted 1:20), $0.5 \mu \mathrm{l}$ of each $10 \mu \mathrm{M}$ primer, $12.5 \mu \mathrm{l}$ OneTaq Hot-Start 2X Master Mix (New England Biolabs) and a cycling program consisting of: initial denaturing at $94{ }^{\circ} \mathrm{C}(1 \mathrm{~min}), 30$ cycles of 95 ${ }^{\circ} \mathrm{C}(30 \mathrm{sec}), 52{ }^{\circ} \mathrm{C}(30 \mathrm{sec})$ and $68^{\circ} \mathrm{C}(30 \mathrm{sec})$ and a final elongation stage of $68^{\circ} \mathrm{C}(5 \mathrm{~min})$. PCR reactions were carried out in triplicate for each sample and were individually checked for successful amplification using gel electrophoresis. The individual PCR reactions for each sample were cleaned and normalized to $2.5 \mathrm{ng} \mu \mathrm{l}^{-1}$ using a Just-a-Plate, 96 well normalization and purification plate (Charm Biotech). Samples were then pooled and sequenced using Illumina MiSeq paired-end sequencing ( 2 x 300 bp) at the Stanford Functional Genomics Facility. Raw sequence data were deposited in the NCBI short read archive under BioProject ID PRJNA548137. 


\section{Bioinformatics}

Preliminary analyses suggested that the reverse read quality was poor, so only the forward reads were used for all analyses. Raw reads were first trimmed to remove $3^{\prime}$ gene primer and sequencing adapter contamination using cutadapt (Martin 2011). The trimmed reads were then pooled and denoised using DADA2 (Callahan et al. 2016), excluding reads with an expected error rate $>2 \mathrm{bp}$, a length $<75 \mathrm{bp}$, and putative chimeric sequences. Denoised reads were then collapsed to $99 \%$ operational taxonomic units (OTUs) using agglomerative, single-linkage clustering implemented in DECIPHER (Wright, Erik 2016). The OTU table was then filtered of likely contaminants by removing any OTU with an average abundance across all samples that was less than the maximum abundance in any of the negative controls.

Taxonomic predictions for OTUs were made using the $D A D A 2$ implementation of the RDP classifier (Wang et al. 2007) trained on the UNITE v8.2 species hypothesis database (Abarenkov, Kessy; Zirk, Allan; Piirmann, Timo; Pöhönen, Raivo; Ivanov, Filipp; Nilsson, R. Henrik; Kõljalg 2020). Because a prominent group of ErMF, known as the Rhizoscyphus ericae aggregate, or REA (三 Hymenoscyphus ericae aggregate; Vrålstad, Fossheim and Schumacher 2000; Vrålstad, Myhre and Schumacher 2002; Hambleton and Sigler 2005), has undergone numerous taxonomic revisions, we manually curated the relevant taxonomy in the training data. We resolved inconsistencies in this clade following the most recent updates reported by Fehrer et al. (2019), which consolidated members of the REA in the genus Hyaloscypha.

Identification of potential ErMF in the OTU database was complicated by two factors. First, the short read length and high variability of the ITS region, combined with limited 
representation of both Hawaiian root / soil associated fungi and fungi associated with ericaceous plants in current reference databases resulted in low confidence for fine scale taxonomic assignments. Second, there is significant uncertainty about the taxonomic range of fungal species capable of forming ErM. We chose an inclusive approach, defining the subset of putative ErMF to include all OTUs assigned to fungal orders reported to include ericoid fungi (Leopold 2016). This approach is likely to include many non-mycorrhizal endophytes, particularly in the order Helotiales, however some of these species likely have overlapping functional attributes with ErMF (Newsham 2011) and it is not currently possible to distinguish ErMF taxa with sequence data alone. An alternative approach, manually curating putative ErMF OTUs by looking at the sources of the individual sequences comprising the closest matching UNITE species hypotheses yielded qualitatively similar results. We focus here on the approach using fungal orders as it is more easily replicated.

\section{Statistical analysis of chronosequence data}

To assess if fungal diversity changed across the LSAG, we estimated alpha diversity at the sample level for both the complete data set and the subset of putative ErMF. To account for unequal sequencing depth among samples we estimated alpha diversity using Hill numbers, or the effective number of species, at a sampling depth of 5000 sequences per sample using the Rpackage iNEXT (Chao et al. 2014; Hsieh, Ma and Chao 2016). We calculated Hill numbers for each sample using a scaling of 0 (equivalent to species richness) and a scaling of 1 (equivalent to the exponent of Shannon entropy, or Shannon diversity) and analyzed the results in parallel. 
Variation in alpha diversity among chronosequence sites was tested using ANOVAs and $F$-tests, followed by Tukey's HSD post-hoc tests.

To determine how the composition of fungal communities changed across the LSAG, we first calculated Bray-Curtis dissimilarity among samples using the proportional abundance of OTUs in each sample to account for unequal sampling depth (McMurdie and Holmes 2014). We initially tested alternative dissimilarity metrics, including the binary Jaccard distance, the probabilistic Raup-Crick distance, and the information-theoretic based Jensen-Shannon Divergence, and found that all produced qualitatively similar results to those obtained with BrayCurtis dissimilarity, which we will focus on here. Dissimilarities were visualized using nonmetric multidimensional scaling (NMDS) implemented in the R-package vegan (Oksanen et al. 2017). Contours representing increasing site age were fit to the 2-dimensional NMDS ordination, using the vegan function ordisurf, to aid interpretation of species turnover across the chronosequence. The significance of changes in community composition were tested with a permutational multivariate analysis of variance (Anderson 2001). Both $\log _{10}$-transformed site age and site identity as a factor were used as predictors in perMANOVAs to assess both the significance of variation in community composition among sites and the proportion of this variation that could be explained by turnover along the chronosequence. OTUs occurring at individual LSAG sites with greater abundance and more often than expected by chance alone were identified using indicator species analysis (Dufrêne and Legendre 1997) using the Rpackage labdsv (Roberts 2013), and visualized on a bipartite graph of the 50 most abundant OTUs. 


\section{Statistical analysis of fertilizer plot data}

To test the effects of fertilization on fungal composition and diversity, we analyzed both the complete data set and the subset of putative ErMF OTUs from the fertilizer addition plots at the $300 \mathrm{yr}$ and 4.1 myr LSAG sites. We followed the procedure described above to estimate fungal richness and Shannon diversity and then used ANOVAs and $F$-tests to assess the direct and interactive effects of $\mathrm{N}$ and $\mathrm{P}$ addition. Preliminary analysis indicated that the fungal richness and diversity associated with pairs of plants sampled from the same plot were not more similar than those between plots with the same fertilizer treatments, so analyses were conducted at the level of individual plants $(n=32)$, rather than fertilization plots $(n=16)$. To test whether community composition was affected by fertilization, we used NMDS and permutational MANOVAs of Bray-Curtis dissimilarity calculated on proportional OTU abundance.

\section{Reproducibility of analyses}

All statistical analyses were conducted in the R v4.2 statistical computing environment (R Core Team 2020), using the package tidyverse (Wickham et al. 2019) for general data manipulation and phyloseq (McMurdie and Holmes 2013) to manipulate OTU tables and associated metadata. Code for reproducing all bioinformatic processing, statistical analyses and figures, along with all necessary sample metadata, has been publicly archived (DOI: 10.5281/zenodo.3979769).

\section{Results}

Identification of fungal OTUs 

processing, from which we identified 685 fungal OTUs. The subset of putative ErMF included $30.8 \%$ of the total OTUs, and accounted for $66.5 \%$ of all sequences. Many taxa could not be confidently assigned to genera or family (Fig. 2), and the lack of high similarity matches for many OTUs in the UNITE database suggests the presence of many novel taxa. For example, the most abundant taxon we identified (OTU.1) shares only $85 \%$ sequence similarity with the nearest sequence in the UNITE database and could not be confidently assigned beyond the order Helotiales. The second most abundant taxon (OTU.2) was assigned to the order Trechisporales and shares $99 \%$ sequence similarity with a UNITE species hypothesis that contains only a few individuals sequenced without culturing from the roots of plants in the Orchidaceae and Clustaceae, originating from Eastern Africa and Taiwan. However, the next closest UNITE species hypothesis in the Trechisporales shares only $75 \%$ sequence similarity, suggesting that this is could be a specious taxonomic assignment (see discussion, below). We did identify numerous taxa with affinities to the globally widespread Rhizoscyphus ericae aggregate (三 Hymenoscyphus ericae aggregate; Vrålstad, Fossheim and Schumacher 2000; Vrålstad, Myhre and Schumacher 2002; Hambleton and Sigler 2005), including the common ErMF, Hyaloscypha hepaticicola $(\equiv$ Rhizoscyphus ericae \& $\equiv$ Pezoloma ericae; Fehrer et al. 2019), though this taxon was notably absent at the youngest site (Fig. 2). The common ErMF species, Oidiodendron maius, was only observed in very low abundance in the sequence data, primarily in samples from the oldest chronosequence site. No members of the Sebacinales were observed, despite their common occurrence as root endophytes and ErMF on ericaceous plants (Selosse et al. 2007; Weiß et al. 2011). 
264

82

Site age effects on fungal diversity and composition

Fungal richness and diversity were greatest in $V$. calycinum roots collected from the oldest chronosequence sites (Fig. 3). When all fungi were considered together (Fig. 3a), variation in OTU richness $\left(F_{4,55}=5.14 ; p=0.001\right)$ was primarily the result of lower richness in the more fertile, middle-aged sites, while variation Shannon diversity $\left(F_{4,55}=11.9 ; p<0.001\right)$ was primarily due to greater richness at the oldest site. For putative ErMF (Fig. 3b), variation in OTU richness $\left(F_{4,54}=5.62 ; p<0.001\right)$ was the result of an increase at the two oldest sites, relative to the younger sites, while variation in Shannon diversity $\left(F_{4,54}=11.4 ; p<0.001\right)$ was the result of a progressive increase with site age.

Fungal communities associated with $V$. calycinum roots differed in composition among chronosequence sites for all fungi $\left(F_{4,55}=6.92, r^{2}=0.33, p<0.001\right)$ and the subset of putative $\operatorname{ErMF}\left(F_{4,55}=9.42, r^{2}=0.40, p<0.001\right)$. Similarly aged sites tended to have more similar OTU compositions (Fig. 4), and site age explained roughly a third of the variation in OTU composition that was attributed to variation among sites, both for all fungi $\left(F_{1,58}=7.64, r^{2}=0.12\right.$, $p<0.001)$ and putative ErMF $\left(F_{1,58}=9.41 r^{2}=0.14, p<0.001\right)$. In addition, while many of the most abundant OTUs were broadly distributed across the chronosequence, occurring in most or all sites, distribution patterns varied among taxa and many could be identified as being significantly associated with individual LSAG sites (Fig. 2).

Fertilization effects on fungal composition and diversity 
The effect of fertilization on fungal richness and diversity depended on site (Fig. 5;

Tables S1 \& S2). At the 300 yr-old site, the addition of $\mathrm{N}$ reduced both richness and Shannon diversity for all fungi $\left(F_{1,28}=10.1 ; p=0.004 \& F_{1,28}=5.95 ; p=0.02\right.$, respectively $)$. For putative ErMF, the addition of $\mathrm{N}$ at the $300 \mathrm{yr}$-old site also reduced OTU richness $\left(F_{1,28}=12.9 ; p=\right.$ $0.001)$, and marginally reduced Shannon diversity $\left(F_{1,28}=3.37 ; p=0.08\right)$. In contrast, at the 4.1 myr site it was the addition of $\mathrm{P}$ that reduced OTU richness and Shannon diversity for all fungi $\left(F_{1,28}=6.65 ; p=0.02 \& F_{1,28}=15.8 ; p<0.001\right.$, respectively $)$ and putative ErMF $\left(F_{1,28}=3.60 ; p\right.$ $=0.07 \& F_{1,28}=8.7 ; p=0.006$, respectively).

In contrast to richness and diversity, fungal community composition was not primarily impacted by addition of the limiting nutrient at each site (Table 1; Fig. S1). Instead, both $\mathrm{N}$ and $\mathrm{P}$ additions affected fungal composition, but $\mathrm{P}$ addition had the greatest impact on composition at both sites, for all fungi and the subset of putative ErMF.

\section{Discussion}

Consistent with our initial hypothesis, we found that $V$. calycinum associates with more putative ErMF in sites with older soils. This pattern was not simply the result of increasing richness, but also greater evenness, which could reflect increased niche partitioning in response to the accumulation of soil organic matter and the development of a structured organic soil horizon during pedogenesis (Goh et al. 1976; Torn et al. 1997). Although speculative, this explanation is consistent with the fact that ErMF taxa can vary in their affinity for specific nutrient sources (Cairney et al. 2000; Whittaker and Cairney 2001; Grelet, Meharg and Alexander 2005; Grelet et al. 2009b) and can be spatially structured across soil layers 
306

(Wurzburger, Higgins and Hendrick 2012). However, it is also possible that dispersal limitation (Cline and Zak 2014) and in-situ diversification (Gillespie 2016) contributed to the greater diversity observed in older sites and manipulative experiments would be needed to quantify the role of niche partitioning relative to other factors.

Results from our fertilization experiment suggest that soil-age related nutrient limitation influenced fungal richness and diversity. Specifically, we found that richness and diversity decreased in response to the addition of $\mathrm{N}$ and $\mathrm{P}$ at the youngest and oldest chronosequence sites, respectively. Previous studies have shown that plant growth is limited by $\mathrm{N}$ at the $300 \mathrm{yr}$ site and P at the 4.1 myr site (Vitousek 2004), and P limits rates of litter decomposition and soil organic matter processing in the 4.1 myr site (Hobbie and Vitousek 2000; Reed, Vitousek and Cleveland 2011). Moreover, Treseder and Allen (2002) found that growth of arbuscular mycorrhizal fungi associating with non-ericaceous plants in this system is directly N-limited at the $300 \mathrm{yr}$ site and P-limited at the 4.1 myr site. Our results could suggest that ErMF, in contrast with arbuscular mycorrhizal fungi, are not directly limited by $\mathrm{N}$ and P availability in the LSAG, possibly due to their ability to access recalcitrant organic nutrient pools (Read 1983, 1991; Perotto, Daghino and Martino 2018). Instead, fertilizer addition may cause the host plant to reallocate resources (i.e., carbon-rich photosynthates) away from root-associated symbionts (Olsson, Rahm and Aliasgharzad 2010; Kiers et al. 2011; Konvalinková et al. 2017), resulting in reduced fungal richness and diversity in the rhizosphere. This possibility could have significant implications for stability of ERM symbioses in the context of anthropogenic nutrient deposition in the nutrientpoor habitats where ericaceous plant often thrive (Van Geel et al. 2020). 
Although we observed a clear pattern of turnover in species composition across the soil

328

330

331

332

333

334

335

336

337

338

339

340

341

342

chronosequence (Fig. 4), results from our fertilization experiment suggest that host and ecosystem-level nutrient limitation are not the primary determinants of fungal species composition in this system (Table 1). This could be because dispersal limitation restricts the pools of ErMF species present at each site (Hutton et al. 1997), limiting the effect of localized nutrient additions. Nonetheless, both $\mathrm{N}$ and $\mathrm{P}$ additions did influence fungal community composition at both sites, though the effects of $\mathrm{P}$ additions were consistently larger, even at the N-limited site. Previous work in this system has shown that fertilization with $\mathrm{P}$ at the $4.1 \mathrm{myr}$ site significantly affects litter chemistry, whereas fertilization with $\mathrm{N}$ at the $300 \mathrm{yr}$ site does not (Harrington, Fownes and Vitousek 2001). Because ericaceous root systems occur predominantly in the upper, organic soil layers, where ErMF directly access recalcitrant litter-nutrient inputs (Read, Leake and Perez-Moreno 2004), changes in litter chemistry may explain why the strongest fertilization effects we observed for putative ErMF with P addition at the 4.1 myr site. These results are in contrast with the common characterization of ErM symbioses as being primarily N driven (Read 1991) and highlight the relative lack of data from P-limited tropical systems.

We do not have the histological data to determine the morphology of fungal interactions with $V$. calycinum and definitively determine the mycorrhizal status of the fungal OTUs we identified. However, our results suggest that many novel ErMF species could occur in this system. For example, the two most abundant OTUs in our study, which accounted for $32 \%$ of all reads across the chronosequence and $64 \%$ of the reads at the youngest site (Fig. 2), were not closely related to any well-described ErMF species. Although the most abundant OTU shared 
only $85 \%$ sequence similarity with the nearest taxon in the UNITE database, which comprises a large group of poorly classified Helotiales, many of the most similar taxa were isolated from the roots of ErM or ecto-mycorrhizal plants, which can host ErMF as endophytes or mycorrhizal fungi capable of forming both ecto- and ericoid mycorrhizae (Villarreal-Ruiz, Anderson and Alexander 2004; Vrålstad 2004; Grelet et al. 2009a; Villarreal-Ruiz et al. 2012; Vohník et al. 2013). There also is considerable reason to doubt the taxonomic prediction for the second most abundant OTU as Trechisporales. A mycorrhizal symbiont forming a unique, sheathed-ericoid mycorrhizal symbiosis in Norway was also originally thought to be most closely related to the Trechisporales (Vohník et al. 2012). This taxon was later identified as Kurtia argillacea, in the Hymenochaetales, based on multi-gene phylogenetic analyses, which showed that proper taxonomic placement using nrDNA genes was not possible for this taxon (Kolařík and Vohník 2018). Although taxon (OTU.2) does not share any substantive sequence similarity with the one available ITS sequence for Kurtia argillacea, it does share some characteristics, including an elevated GC content (57\%), which Kolařík and Vohník (2018) suggest could be the result of a non-standard substitution rate, possibly related to the transition to a mycorrhizal lifestyle. Culture-based investigations of this taxon, and other novel taxa associated with Hawaiian ericaceous plant, are needed to definitively address the possibility that our data set includes novel ErMF. Although it is also possible that some of these species are non-mycorrhizal endophytes, this does not preclude a role in nutrient uptake.

In summary, we have shown that the diversity of fungi associated with the roots of ericaceous plants increases throughout long-term soil development largely due to increasing richness and evenness of putative ErMF taxa. Our results contrast with recent reports of a hump- 
371 shaped diversity pattern with increasing soil age for arbuscular mycorrhizal fungi (Krüger et al.

372 2015), suggesting that functional differences among types of mycorrhizal fungi may determine

373 the response of root-associated fungi to long-term soil development. We have also shown that P

374 availability can affect the species composition and community structure of ericoid fungi,

375 particularly in older P-limited ecosystems. Our results suggest that further study of ErMF from

376 P-limited systems or across long-term soil chronosequences may prove valuable for identifying

377 the extent of taxonomic and functional diversity for this unique group of mycorrhizal fungi.

Funding

This work as supported by Stanford University, Department of Biology, and student

research grants from the American Society of Naturalists and the Mycological Society of America.

\section{Acknowledgments}

We thank Michael Shintaku at the University of Hawaii, Hilo, College of Agriculture,

Forestry and Natural Resource Management and Anne Veillet at the Evolutionary Genomics

Core Facility for access to laboratory space and equipment. We also thank Matt Knope for

feedback on earlier drafts of this manuscript. Site access was granted by the Hawaii Division of 


\section{References}

Abarenkov, Kessy; Zirk, Allan; Piirmann, Timo; Pöhönen, Raivo; Ivanov, Filipp; Nilsson, R. Henrik; Kõljalg U. UNITE general FASTA release for Fungi. 2020. DOI: 10.15156/BIO/786369.

Adamczyk B, Ahvenainen A, Sietiö O-M et al. The contribution of ericoid plants to soil nitrogen chemistry and organic matter decomposition in boreal forest soil. Soil Biol Biochem 2016;103:394-404.

Anderson MJ. A new method for non-parametric multivariate analysis of variance. Austral Ecol 2001;26:32-46.

Cairney JWG, Meharg AA. Ericoid mycorrhiza: a partnership that exploits harsh edaphic conditions. Eur J Soil Sci 2003;54:735-40.

Cairney JWG, Sawyer NA, Sharples JM et al. Intraspecific variation in nitrogen source utilisation by isolates of the ericoid mycorrhizal fungus Hymenoscyphus Ericae (Read) Korf and Kernan. Soil Biol Biochem 2000;32:1319-22.

Callahan BJ, McMurdie PJ, Rosen MJ et al. DADA2: High-resolution sample inference from Illumina amplicon data. Nat Methods 2016;13:581-3.

Chadwick OA, Derry LA, Vitousek PM et al. Changing sources of nutrients during four million years of ecosystem development. Nature 1999;397:491-7.

Chao A, Gotelli NJ, Hsieh TC et al. Rarefaction and extrapolation with Hill numbers: a framework for sampling and estimation in species diversity studies. Ecol Monogr 2014;84:45-67.

Clemmensen KE, Bahr A, Ovaskainen $\mathrm{O}$ et al. Roots and associated fungi drive long-term carbon sequestration in boreal forest. Science (80- ) 2013;339:1615-8.

Clemmensen KE, Finlay RD, Dahlberg A et al. Carbon sequestration is related to mycorrhizal fungal community shifts during long-term succession in boreal forests. New Phytol 2015;205:1525-36.

Cline LC, Zak DR. Dispersal limitation structures fungal community assembly in a long-term glacial chronosequence. Environ Microbiol 2014;16:1538-48.

Crews TE, Kitayama K, Fownes JH et al. Changes in soil phosphorus fractions and ecosystem dynamics across a long chronosequence in Hawaii. Ecology 1995;76:1407-24. 
DeForest JL, Scott LG. Available organic soil phosphorus has an important influence on microbial community composition. Soil Sci Soc Am J 2010;74:2059.

Dickie IA, Martínez-García LB, Koele N et al. Mycorrhizas and mycorrhizal fungal communities throughout ecosystem development. Plant Soil 2013;367:11-39.

Dufrêne M, Legendre P. Species Assembledges and indicator species: the need for a flexible asymmetrical approach. Ecol Monogr 1997;67:345-66.

Fehrer J, Réblová M, Bambasová V et al. The root-symbiotic Rhizoscyphus ericae aggregate and Hyaloscypha (Leotiomycetes) are congeneric: phylogenetic and experimental evidence. Stud Mycol 2019;92:195-225.

Fukami T, Wardle DA. Long-term ecological dynamics: reciprocal insights from natural and anthropogenic gradients. Proc Biol Sci 2005;272:2105-15.

Van Geel M, Jacquemyn H, Peeters G et al. Diversity and community structure of ericoid mycorrhizal fungi in European bogs and heathlands across a gradient of nitrogen deposition. New Phytol 2020, DOI: 10.1111/nph.16789.

Gillespie RG. Island time and the interplay between ecology and evolution in species diversification. Evol Appl 2016;9:53-73.

Goh KM, Rafter TA, Stout JD et al. The accumulation of soil organic matter and its carbon isotope content in a chronosequence of soils developed on aeolian sand in New Zealand. $J$ Soil Sci 1976;27:89-100.

Grelet G-A, Johnson D, Paterson E et al. Reciprocal carbon and nitrogen transfer between an ericaceous dwarf shrub and fungi isolated from Piceirhiza bicolorata ectomycorrhizas. New Phytol 2009a;182:359-66.

Grelet G-A, Meharg A a., Alexander IJ. Carbon availability affects nitrogen source utilisation by Hymenoscyphus ericae. Mycol Res 2005;109:469-77.

Grelet G-A, Meharg AA, Duff EI et al. Small genetic differences between ericoid mycorrhizal fungi affect nitrogen uptake by Vaccinium. New Phytol 2009b;181:708-18.

Hambleton S, Sigler L. Meliniomyces, a new anamorph genus for root-associated fungi with phylogenetic affinities to Rhizoscyphus ericae (三 Hymenoscyphus ericae), Leotiomycetes. Stud Mycol 2005;53:1-27.

Harrington RA, Fownes JH, Vitousek PM. Production and resource use efficiencies in N- and Plimited tropical forests: a comparison of responses to long-term fertilization. Ecosystems 2001;4:646-57. 
Hazard C, Gosling P, Mitchell DT et al. Diversity of fungi associated with hair roots of ericaceous plants is affected by land use. FEMS Microbiol Ecol 2014;87:586-600.

Herbert D a., Fownes JH. Phosphorus limitation of forest leaf area and net primary production on a highly weathered soil. Biogeochemistry 1995;29:223-35.

Hobbie SE, Vitousek PM. Nutrient limitation of decomposition in Hawaiian forests. Ecology 2000;81:1867-77.

Hsieh TC, Ma KH, Chao A. iNEXT: interpolation and extrapolation for species diversity. R package version 2.0.8. R-project 2016:1-18.

Hutton BJ, Dixon KW, Sivasithamparam K et al. Effect of habitat disturbance on inoculum potential of ericoid endophytes of Western Australian heaths (Epacridaceae). New Phytol 1997;135:739-44.

Ishida TA, Nordin A. No evidence that nitrogen enrichment affect fungal communities of Vaccinium roots in two contrasting boreal forest types. Soil Biol Biochem 2010;42:234-43.

Johnson NC, Wilson GWT, Bowker MA et al. Resource limitation is a driver of local adaptation in mycorrhizal symbioses. Proc Natl Acad Sci 2010;107:2093-8.

Kiers ET, Duhamel M, Beesetty Y et al. Reciprocal rewards stabilize cooperation in the mycorrhizal symbiosis. Science 2011;333:880-2.

Kitayama K, Mueller-Dombois D. Vegetation changes along gradients of long-term soil development in the Hawaiian montane rainforest zone. Vegetatio 1995;120:1-20.

Kohout P. Biogeography of ericoid mycorrhiza. In: Tedersoo L (ed.). Biogeography of Mycorrhizal Symbiosis. Springer, 2017, 179-93.

Kolařík M, Vohník M. When the ribosomal DNA does not tell the truth: the case of the taxonomic position of Kurtia argillacea, an ericoid mycorrhizal fungus residing among Hymenochaetales. Fungal Biol 2018;122:1-18.

Konvalinková T, Püschel D, Řezáčová V et al. Carbon flow from plant to arbuscular mycorrhizal fungi is reduced under phosphorus fertilization. Plant Soil 2017;419:319-33.

Koske RE, Gemma JN, Flynn T. Mycorrhizae in Hawaiian angiosperms: a survey with implications for the origin of the native flora. Am J Bot 1992;79:853-62.

Krüger M, Teste FP, Laliberté E et al. The rise and fall of arbuscular mycorrhizal fungal diversity during ecosystem retrogression. Mol Ecol 2015;24:4912-30. 
Lambers H, Raven JA, Shaver GR et al. Plant nutrient-acquisition strategies change with soil age. Trends Ecol Evol 2008;23:95-103.

Leake JR, Read DJ. Experiments with ericoid mycorrhiza. Methods Microbiol 1991;23:435-57.

Leopold DR. Ericoid fungal diversity: challenges and opportunities for mycorrhizal research. Fungal Ecol 2016;24:114-23.

Martin M. Cutadapt removes adapter sequences from high-throughput sequencing reads. EMBnet.journal 2011;17:10.

Martínez-García LB, Richardson SJ, Tylianakis JM et al. Host identity is a dominant driver of mycorrhizal fungal community composition during ecosystem development. New Phytol 2015;205:1565-76.

McMurdie PJ, Holmes S. phyloseq: An R package for reproducible interactive analysis and graphics of microbiome census data. Watson M (ed.). PLoS One 2013;8:e61217.

McMurdie PJ, Holmes S. Waste not, want not: why rarefying microbiome data is inadmissible. McHardy AC (ed.). PLoS Comput Biol 2014;10:e1003531.

Mitchell DT, Gibson BR. Ericoid mycorrhizal association: ability to adapt to a broad range of habitats. Mycologist 2006;20:2-9.

Myers MD, Leake JR. Phosphodiesters as mycorrhizal P sources II. Ericoid mycorrhiza and the utilization of nuclei as a phosphorus and nitrogen source by Vaccinium macrocarpon. New Phytol 1996;132:445-51.

Nasholm T, Ekblad A, Nordin A et al. Boreal forest plants take up organic nitrogen. Nature 1998;392:914-6.

Newsham KK. A meta-analysis of plant responses to dark septate root endophytes. New Phytol 2011;190:783-93.

Oksanen J, Blanchet FG, Friendly M et al. Package 'vegan' | Community Ecology Package.' 2017:1-292.

Olsson PA, Rahm J, Aliasgharzad N. Carbon dynamics in mycorrhizal symbioses is linked to carbon costs and phosphorus benefits. FEMS Microbiol Ecol 2010;72:125-31.

Pearson V, Read DJ. Biology of mycorrhiza in the Ericaceae II. The transport of carbon and phosphorus by the endophyte and the mycorrhiza. New Phytol 1973;72:1325-31.

Peltzer DA, Wardle DA, Allison VJ et al. Understanding ecosystem retrogression. Ecol Monogr 2010;80:509-29. 
Perotto S, Daghino S, Martino E. Ericoid mycorrhizal fungi and their genomes: another side to the mycorrhizal symbiosis? New Phytol 2018;220:1141-7.

Perotto S, Martino E, Abba S et al. Genetic diversity and functional aspects of ericoid mycorrhizal fungi. In: Hock B (ed.). Fungal Associations 2nd. 2nd ed. Springer Berlin Heidelberg, 2012, 255-85.

Read DJ. The biology of mycorrhiza in the Ericales. Can J Bot 1983;61:985-1004.

Read DJ. Mycorrhizas in ecosystems. Experientia 1991;47:376-91.

Reed SC, Vitousek PM, Cleveland CC. Are patterns in nutrient limitation belowground consistent with those aboveground: results from a 4 million year chronosequence. Biogeochemistry 2011;106:323-36.

Richardson SJ, Peltzer DA, Allen RB et al. Rapid development of phosphorus limitation in temperate rainforest along the Franz Josef soil chronosequence. Oecologia 2004;139:26776.

Roberts DW. labdsv: Ordination and Multivariate Analysis for Ecology. R package version 2.01, 2019. URL: https://CRAN.R-project.org/package=labdsv

Selosse M-A, Setaro S, Glatard F et al. Sebacinales are common mycorrhizal associates of Ericaceae. New Phytol 2007;174:864-78.

Smith DP, Peay KG. Sequence depth, not PCR replication, improves ecological inference from next generation DNA sequencing. PLoS One 2014;9:e90234.

Smith S, Read D. Mycorrhizal Symbiosis. 3rd ed. Academic Press, 2006.

Tamm CO. Nitrogen in Terrestrial Ecosystems. Berlin, Heidelberg: Springer Berlin Heidelberg, 1991.

R Core Team. R: A language and environment for statistical computing. R Foundation for Statistical Computing, Vienna, Austria. URL https://www.R-project.org/. 2020.

Tisserant E, Malbreil M, Kuo A et al. Genome of an arbuscular mycorrhizal fungus provides insight into the oldest plant symbiosis. Proc Natl Acad Sci 2013;110:20117-22.

Torn MS, Trumbore SE, Chadwick OA et al. Mineral control of soil organic carbon storage and turnover. Nature 1997;389:170-3.

Treseder K, Allen M. Direct nitrogen and phosphorus limitation of arbuscular mycorrhizal fungi: a model and field test. New Phytol 2002;155:507-15.

Turner BL. Resource partitioning for soil phosphorus: A hypothesis. $J$ Ecol 2008;96:698-702. 
Villarreal-Ruiz L, Anderson IC, Alexander IJ. Interaction between an isolate from the Hymenoscyphus ericae aggregate and roots of Pinus and Vaccinium. New Phytol 2004;164:183-92.

Villarreal-Ruiz L, Neri-Luna C, Anderson IC et al. In vitro interactions between ectomycorrhizal fungi and ericaceous plants. Symbiosis 2012;56:67-75.

Vitousek P. Nutrient Cycling and Limitations: Hawaii as a Model System. Princeton University Press., 2004.

Vitousek PM, Farrington H. Nutrient limitation and soil development: experimental test of a biogeochemical theory. Biogeochemistry 1997;37:63-75.

Vitousek PM, Howarth RW. Nitrogen limitation on land and in the sea: how can it occur? Biogeochemistry 1991;13:87-115.

Vitousek PM, Walker LR, Whiteaker LD et al. Nutrient limitations to plant growth during primary succession in Hawaii Volcanoes National Park. Biogeochemistry 1993;23:197-215.

Vohník M, Mrnka L, Lukešová T et al. The cultivable endophytic community of Norway spruce ectomycorrhizas from microhabitats lacking ericaceous hosts is dominated by ericoid mycorrhizal Meliniomyces variabilis. Fungal Ecol 2013;6:281-92.

Vohník M, Sadowsky JJ, Kohout P et al. Novel root-fungus symbiosis in Ericaceae: sheathed ericoid mycorrhiza formed by a hitherto undescribed basidiomycete with affinities to Trechisporales. PLoS One 2012;7:e39524.

Vrålstad T. Are ericoid and ectomycorrhizal fungi part of a common guild? New Phytol 2004;164:7-10.

Vrålstad T, Fossheim T, Schumacher T. Piceirhiza bicolorata - the ectomycorrhizal expression of the Hymenoscyphus ericae aggregate? New Phytol 2000;145:549-63.

Vrålstad T, Myhre E, Schumacher T. Molecular diversity and phylogenetic affinities of symbiotic root-associated ascomycetes of the Helotiales in burnt and metal polluted habitats. New Phytol 2002;155:131-48.

Walker LR, Wardle DA, Bardgett RD et al. The use of chronosequences in studies of ecological succession and soil development. J Ecol 2010;98:725-36.

Walker TW, Syers JK. The fate of phosphorus during pedogenesis. Geoderma 1976;15:1-19.

Wang Q, Garrity GM, Tiedje JM et al. Naive Bayesian classifier for rapid assignment of rRNA sequences into the new bacterial taxonomy. Appl Environ Microbiol 2007;73:5261-7. 
576 Wardle DA. Ecosystem properties and forest decline in contrasting long-term chronosequences. Science 2004;305:509-13.

Weiß M, Sýkorová Z, Garnica S et al. Sebacinales everywhere: previously overlooked ubiquitous fungal endophytes. PLoS One 2011;6, DOI: 10.1371/journal.pone.0016793.

580

581

582

583

584

585

586

Whittaker S, Cairney J. Influence of amino acids on biomass production by ericoid mycorrhizal endophytes from Woollsia pungens (Epacridaceae). Mycol Res 2001;105:105-11.

Wickham H, Averick M, Bryan J et al. Welcome to the Tidyverse. J Open Source Softw 2019;4:1686.

Wright, Erik S. Using DECIPHER v2.0 to analyze big biological sequence data in R. $R J$ 2016;8:352.

Wurzburger N, Higgins BP, Hendrick RL. Ericoid mycorrhizal root fungi and their multicopper oxidases from a temperate forest shrub. Ecol Evol 2012;2:65-79.

Xiao G, Berch SM. Organic nitrogen use by salal ericoid mycorrhizal fungi from northern Vancouver Island and impacts on growth in vitro of Gaultheria shallon. Mycorrhiza 1999;9:145-9. 
Table 1: Results of permutational MANOVAs examining the effect of fertilizer addition treatments on the composition of (a) all fungi or (b) putative ErMF associated with $V$. calycinum at the $300 \mathrm{yr}$ and 4.1 myr sites in the Long Substrate Age Gradient chronosequence.

a) All fungi

\begin{tabular}{lllll} 
Site & Treatment & $\boldsymbol{F}$ & $\boldsymbol{r}^{2}$ & $\boldsymbol{P}$ \\
\hline Young (300 yr) & Full model & 1.876 & 0.167 & $<0.001$ \\
& N & 2.284 & 0.068 & 0.003 \\
& P & 2.717 & 0.081 & 0.001 \\
Old (4.1 myr) & Full model & 1.767 & 0.159 & $<0.001$ \\
& N & 1.588 & 0.047 & 0.020 \\
& P & 2.647 & 0.080 & $<0.001$ \\
& N:P & 1.066 & 0.032 & 0.345
\end{tabular}

b) Putative ErMF

\begin{tabular}{lllll} 
Site & Treatment & $\boldsymbol{F}$ & $\boldsymbol{r}^{2}$ & $\boldsymbol{P}$ \\
\hline Young $(300 \mathrm{yr})$ & Full model & 1.787 & 0.160 & 0.007 \\
& N & 1.488 & 0.044 & 0.130 \\
& P & 3.283 & 0.099 & $<0.001$ \\
& N:P & 0.549 & 0.016 & 0.891 \\
Old (4.1 myr) & Full model & 2.324 & 0.199 & $<0.001$ \\
& N & 1.782 & 0.051 & 0.028 \\
& P & 3.592 & 0.103 & $<0.001$ \\
& N:P & 1.600 & 0.046 & 0.060
\end{tabular}




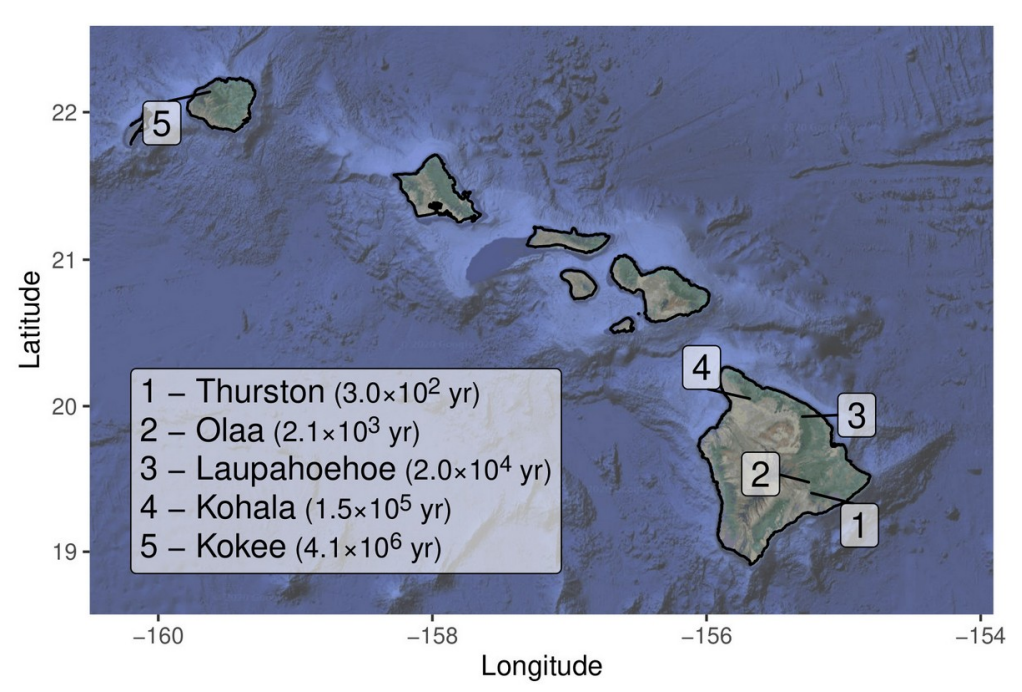

Figure 1: Map of the main Hawaiian Islands showing the locations and ages of the 5 sites in the Long Substrate Age Gradient chronosequence used in the current study. 
bioRxiv preprint doi: https://doi.org/10.1101/2020.08.27.270413; this version posted August 28, 2020. The copyright holder for this preprint (which was not certified by peer review) is the author/funder, who has granted bioRxiv a license to display the preprint in perpetuity. It is made available under aCC-BY 4.0 International license.

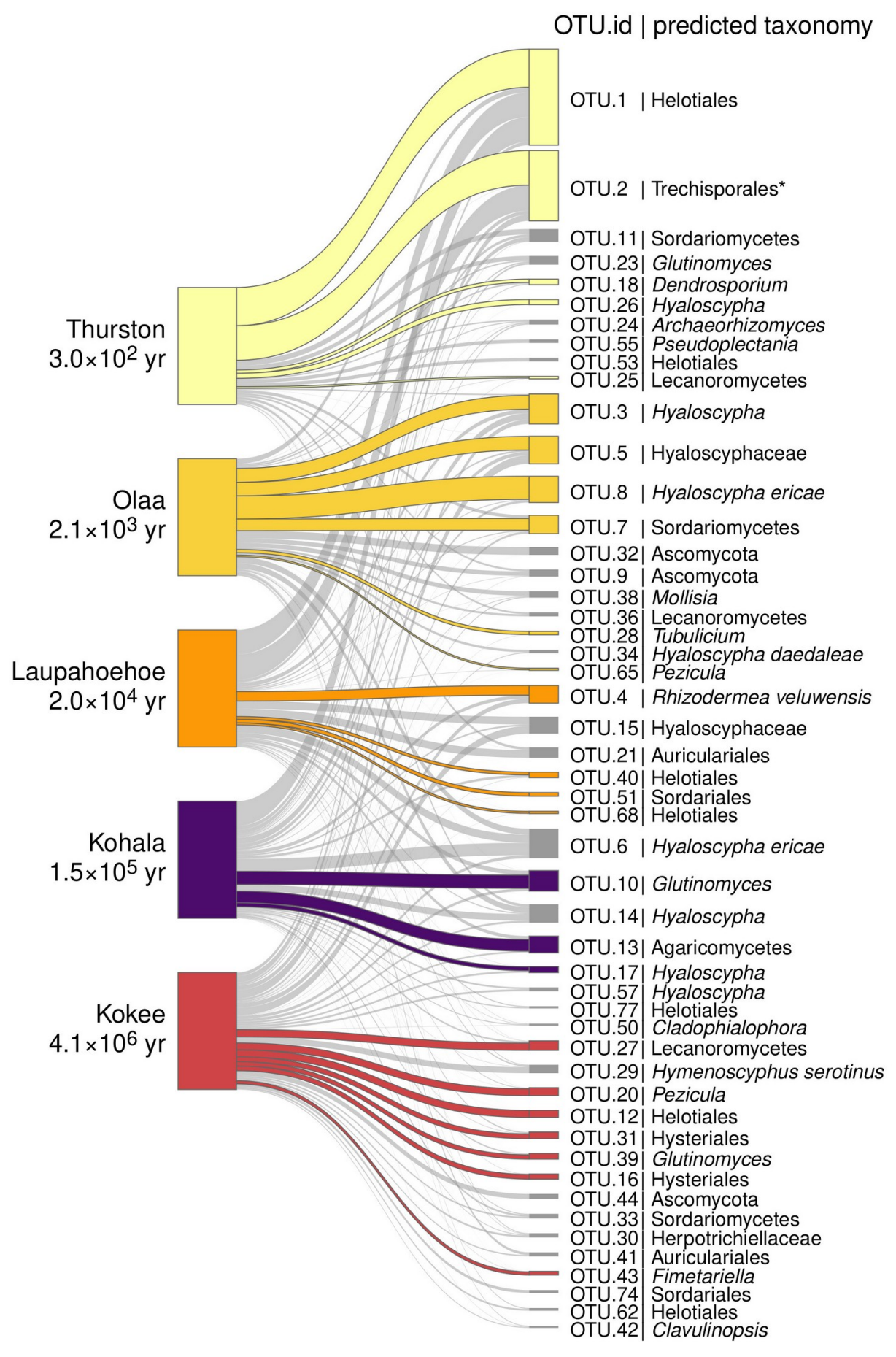

Figure 2: Bipartite network showing the relative abundances of the 50 most common fungal OTUs associated with the roots of Vaccinium calycinum across the Long Substrate Age Gradient. The size of nodes representing OTUs (right) is proportional to their mean abundance in the full data set and the width of connections between OTUs and sites (left) is proportional to their relative abundance at each site. Colored OTU nodes and connections identify significant site associations (indicator species analysis). Taxonomic predictions for each OTU are indicated following the unique OTU identifier. 
(a)

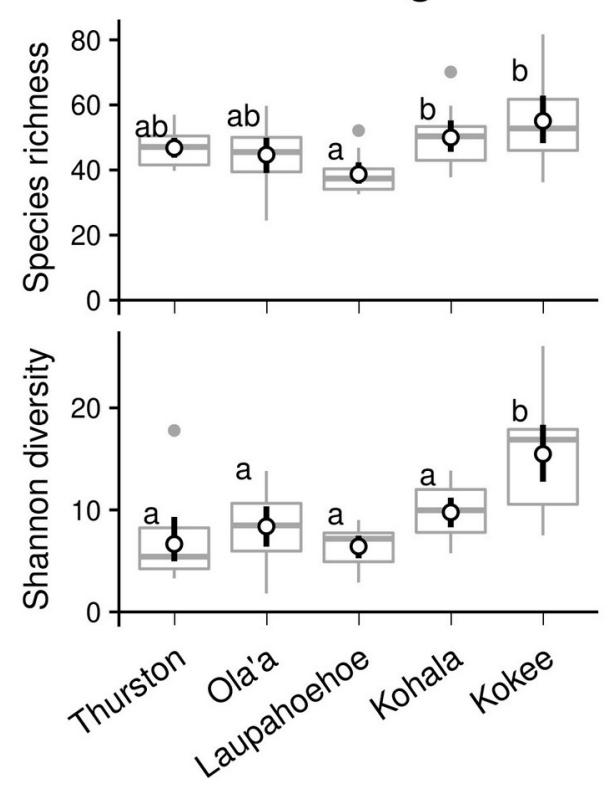

(b)

Putative ErM

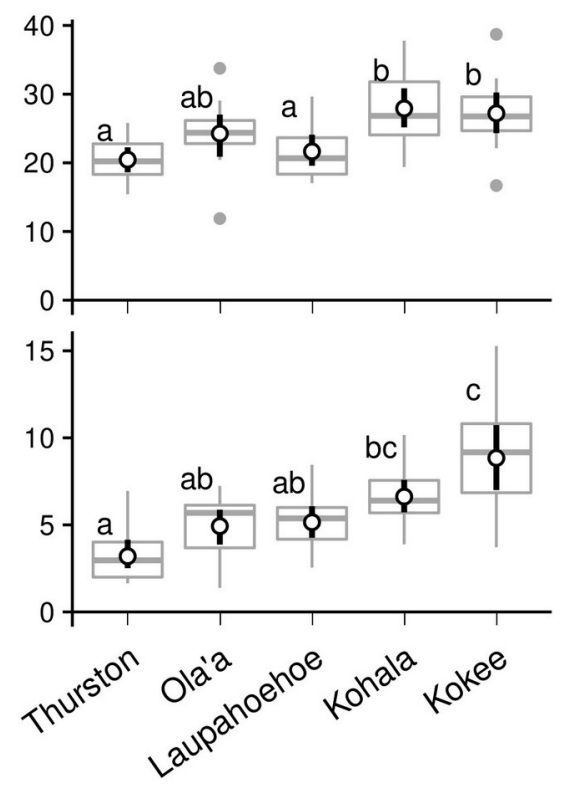

Figure 3: Variation in species richness and Shannon diversity of (a) all fungi and (b) putative ErMF associated with Vaccinium calycinum roots across the Long Substrate Age Gradient. Boxplots show the distribution of the point estimates of richness and diversity for 12 replicate samples at each site. Points indicate the predicted mean ( $\pm 95 \%$ bootstrapped $\mathrm{CI}$ ) species richness or diversity. Letters indicate significant pairwise differences in post-hoc comparisons. 


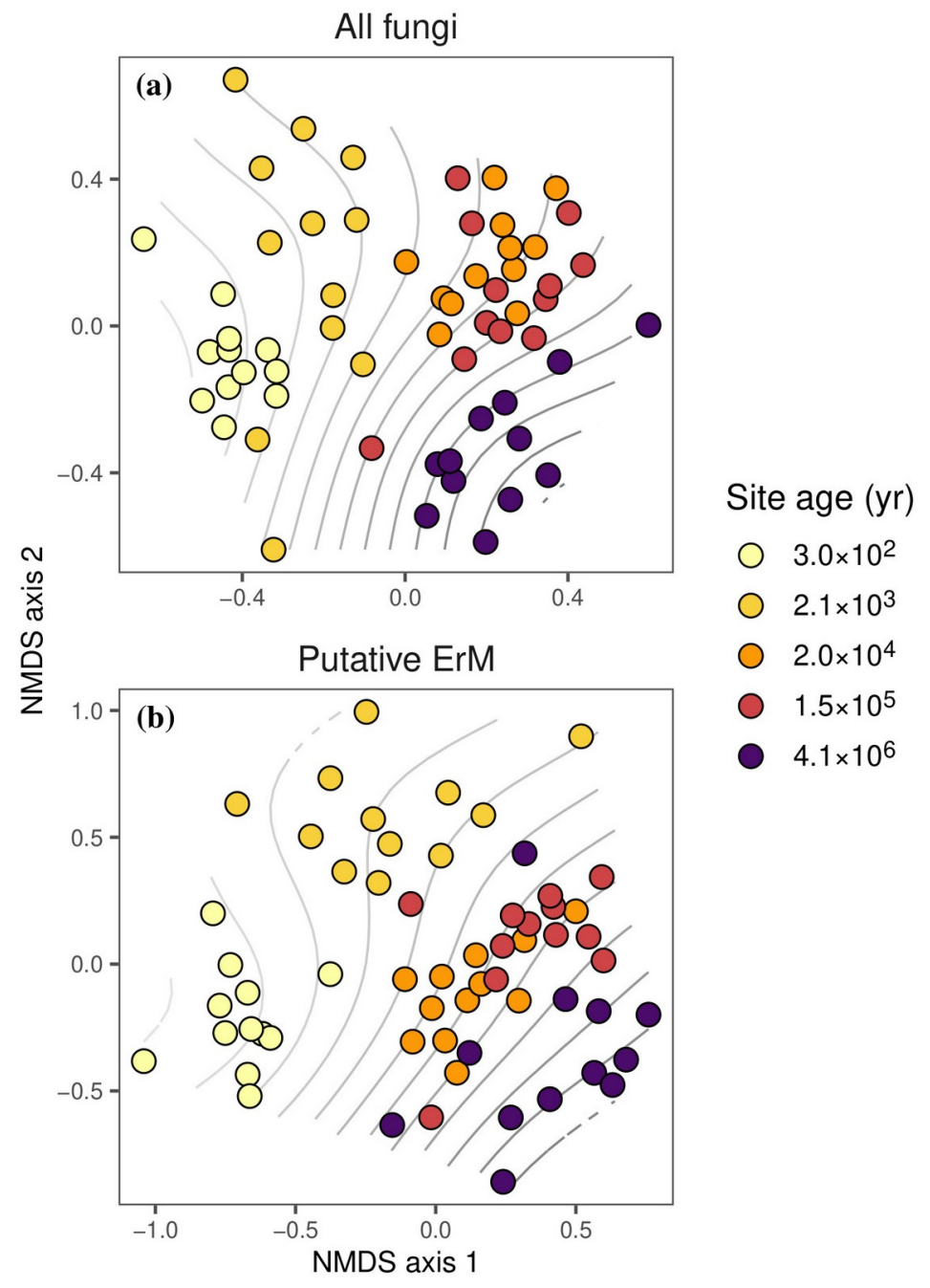

Figure 4: Non-metric multidimensional scaling of community dissimilarity (Jensen Shannon distance) for (a) all fungi (stress $=0.26$ ) and (b) putative ErMF (stress=0.25) associated with Vaccinium calycinum roots collected across a 4.1-myr chronosequence. Points represent individual plants, with color indicating the age of the site where the sample was collected. Contours indicate a smooth surface of $\log _{10}$-transformed site age fit to the ordination space, where increasing site age is indicated by darker contours. 
(a)
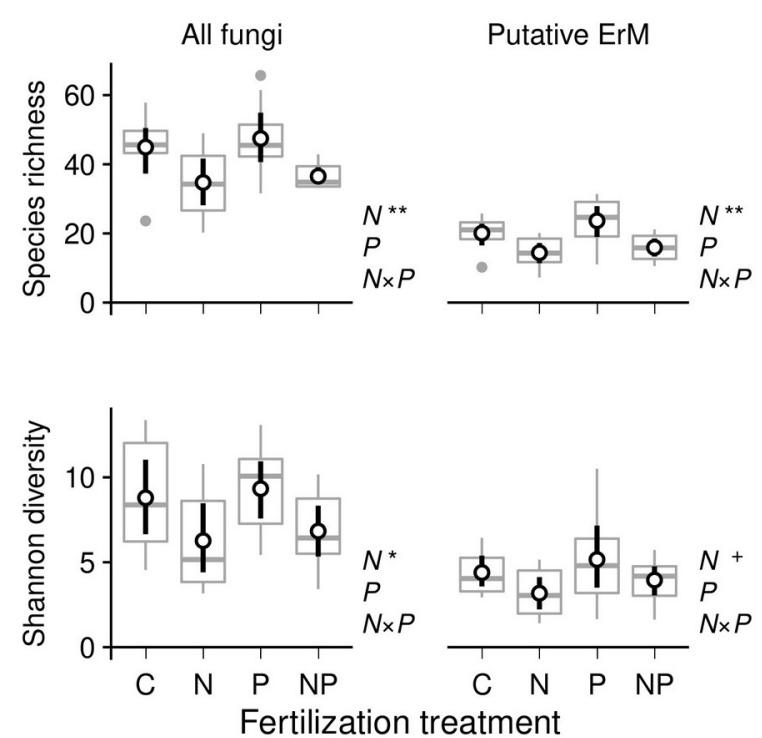

(b) Old (4.1 myr)
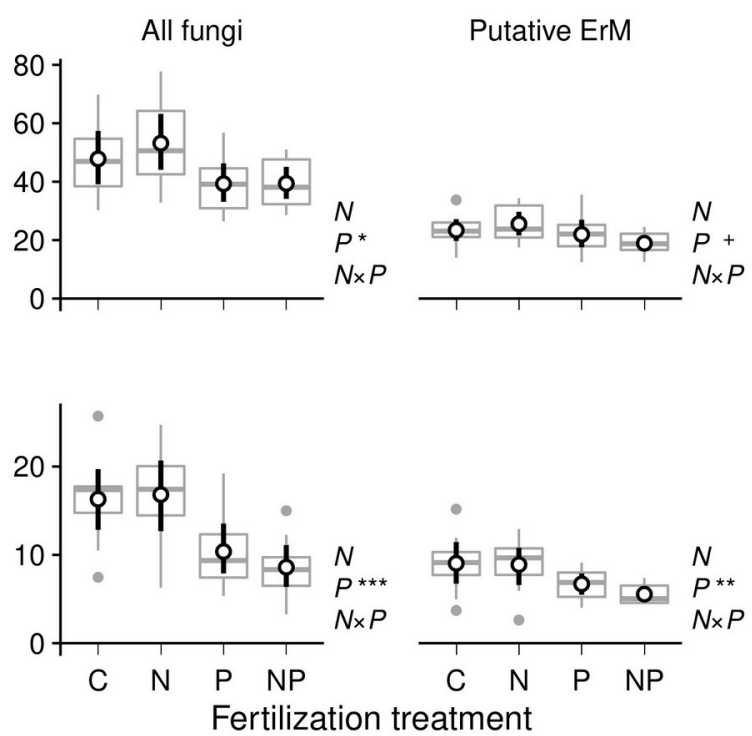

Figure 5: The effect of fertilization with nitrogen $(\mathrm{N})$, phosphorus $(\mathrm{P})$, or both $(\mathrm{NP})$ on the species richness and Shannon diversity of fungal OTUs associated with the roots of Vaccinium calycinum at (a) the $300 \mathrm{yr}$ and (b) the 4.1 myr (b \& d) sites in the Long Substrate Age Gradient chronosequence. Boxplots show the distribution of individual replicate samples and points indicate the predicted mean $( \pm 95 \% \mathrm{CI}$ ) species richness or diversity for each treatment of the unfertilized control (C). Significant direct and interactive effects of $\mathrm{N}$ and $\mathrm{P}$ additions are indicated to the right of each panel, where $+p<0.1,{ }^{*} p<0.05$, ${ }^{* *} p<0.0 .1$, and $* * * p<0.0 .1$. 